Sohannessen, Janne Bondi \& Kristin Hagen (red.) Leksikografi og korpus. En hyllest til Ruth Vatvedt Fjeld, Oslo Studies in Language 11(1), 2020. 77-85. (ISSN 1890-9639 / ISBN 978-82-

http://www.journals.uio.no/osla

\title{
UNDERLIGT NOG/KLOKT NOG - EN GANSKA NY TYP AV SATSADVERB I SVENSKA OCH NORSKA
}

\author{
SVEN-GÖRAN MALMGREN
}

\section{SAMMANFATTNING}

Syftet med studien är att demonstrera hur nya och allt större korpusar kan ge oss djupare insikter i svensk och norsk språkhistoria. Detta illustreras av den ganska nya satsadverbtypen underligt/klokt nog, t.ex. underligt nog var ingen hemma. För att hitta ett förstabelägg för konstruktionstypen år 2000 fanns bara den stora historiska svenska ordboken (SAOB) att tillgå; där hittades ett belägg från 1839. År 2014 var den svenska Litteraturbanken, där stora delar av den klassiska svenska litteraturen finns digitaliserad, redan väl utbyggd, och ett belägg från 1833 hittades. I dag, år 2020, är så gott som alla viktiga svenska tidningar från 1700-talet och framåt digitalt tillgängliga via Kungliga biblioteket, och nu kan konstruktionstypen spåras tillbaka till åtminstone 1805. Som framgår av studien är utvecklingen i Norge och norskan, såväl vad gäller digitala textmaterial som den aktuella konstruktionstypen, i allt väsentligt parallell.

\section{[1] INLEDNING}

I början av 2000-talet ledde jag det Riksbanksfinanserade forskningsprojektet Det svenska ordförrådets utveckling 1800-2000 (ORDAT-projektet, se Malmgren 2000). En av projektets många delstudier gällde utvecklingen av det svenska formordssystemet, särskilt adverben och bland dem inte minst satsadverben (Malmgren 2002). Jag kunde konstatera att det svenska adverbsystemet verkade ha genomgått en kraftig utvidgning under de senaste 200 åren, och fann också i litteraturen belägg för att en sådan utveckling hade paralleller i nära nog alla de västeuropeiska språken (Swan 1991, Ramat \& Ricca 1998).

Arbetet i ORDAT-projektet byggde empiriskt på sin tids elektroniska och ickeelektroniska material: SAOB/OSA (dvs. SAOB i maskinläsbar form), nyordsböcker och andra ordböcker, samt korpusar som mest täckte det moderna språket men som också gjorde vissa nedslag i äldre skeden. I dag, nästan 20 år senare, är läget helt förändrat: den svenska Litteraturbanken växer ständigt och omfattar numera en stor del av den klassiska svenska skönlitteraturen, och under de senaste åren har en annan imponerande resurs blivit tillgänglig, Kungliga bibliotekets 
(KB:s) digitaliserade samling av nästan alla svenska dagstidningar genom mer än 200 år. I Norge tycks man snarast ligga ännu längre fram än i Sverige, särskilt med Nasjonalbibliotekets sajt bokhylla.no.

Ett blygsamt försök att med hjälp av Litteraturbanken bygga vidare på en mindre del av min undersökning från 2002 gjorde jag 2014, innan KB:s tidningsmaterial ännu var tillgängligt (Malmgren 2014). Här ska jag försöka komma ytterligare ett steg längre, denna gång främst med hjälp av KB-materialet och, för en försiktig jämförelse mellan svenska och norska, Nasjonalbibliotekets motsvarande tidningsmaterial. Huvudsyftet är att illustrera vilka möjligheter utvecklingen av de digitala resurserna öppnar för språkhistorikerna, men några preliminära språkliga resultat kommer också att presenteras.

[2] PRESENTATION AV UNDERLIGT/KLOKT NOG-KONSTRUKTIONEN. DESS FÖREKOMST I ÄLDRE SVENSKA KORPUSAR

Artikeln tar liksom Malmgren 2014 sikte på en undergrupp bland de svenska (och nu även norska) satsadverben, här exemplifierade med underligt nog/nok och klokt nog/nok, med följande svenska exempel som lätt kan överföras till norska: ${ }^{1}$

(1) Underligt nog var ingen hemma

(=Ingen var hemma, vilket var underligt)

(2) Klokt nog svarade han inte

(=Han svarade inte, vilket var klokt)

Jag betraktar nog/nok som ett suffix, ${ }^{2}$ varför skenbara fraser som klokt nog kan ses som likvärdiga med ettords-adverb som lyckligtvis, tyvärr m.fl. Det är därför motiverat att kalla underligt nog/nok etc. adverb. Att dessa adverb (som adverbial) är bestämningar till hela satser antyds av parafraserna inom parentes. ${ }^{3}$

Adverben bildade med hjälp av nog/nok (jag använder i fortsättningen termen underligt/klokt nog(/nok)-konstruktioner) möjliggör ett kondenserat uttryckssätt som lämpar sig väl t.ex. för tidningsprosa, och användningen av dem har nära nog exploderat i svenskan och norskan (och säkert även danskan) under de senaste 100-200 åren (förmodligen något tidigare i svenskan än i norskan).

Vilka adverb (ursprungligen adjektiv) kan ingå i underligt/klokt nog-konstruktioner? Huvudsakligen två typer, dels adverb/adjektiv som innebär någon

[1] Här tas enbart bokmål upp, inte nynorska. Eftersom studien delvis hänför sig till tidigt 1800-tal, är termen norska problematisk. Ibland används termen dansk-norska, något som jag dock avstått från här. De texter som ingår i det norska materialet är i varje fall tryckta i Norge och har i allmänhet norska författare.

[2] Bl.a. är det omöjligt att infoga något ord mellan adverbet och nog (*klokt inte nog). Frågan om suffixstatus för nog/nok har emellertid ingen betydelse för den följande framställningen.

[3] Inte heller detta är viktigt för fortsättningen, och jag avstår därför från ytterligare argumentation. 
sorts värdering av den situation, händelse e.d. som omtalas i satsen (underligt, beklagligt, märkvärdigt, sällsamt), ${ }^{4}$ dels adverb/adjektiv som i princip är personbeskrivande och som innehåller ett element av värdering (klokt, elakt, generöst, förmätet, hyggligt), Den första gruppen kallas i fortsättningen situationsvärderande, den andra personvärderande (adverb).

Vi ska nu se vilka möjligheter det har funnits att studera framväxten av underligt/klokt nog(/nok)-konstruktionen i tillgängliga språkliga källor och material, dels 2002, dels 2014, dels slutligen 2020.

Vi går alltså först tillbaka till 2002. För att få en uppfattning om ursprunget för underligt/klokt nog-konstruktionen fanns vid denna tidpunkt i första hand SAOB/OSA att tillgå, och därtill en korpus över tidigare 1800-talssvenska som dock var för liten för att ge något resultat i det här fallet. Men i SAOB hittades ett belägg från 1836 och ett från 1839. Belägget från 1836 bedömde jag som en smula osäkert, men belägget från 1839 (av författaren Almqvist) var otvetydigt:

(3) Bland alla sina tusen omsorger hade han, skam nog [ung. 'genant nog'], glömt bort kofodret.

Sökningar i SAOB:s arkiv gav inget ytterligare resultat. Däremot hittades många belägg från senare delen av 1800-talet, bl.a. i den Strindbergskorpus som redan nu var tillgänglig, och givetvis enorma mängder från 1900-talet.

På grundval av dessa magra data kunde man möjligen formulera en försiktig förmodan att underligt/klokt nog-konstruktionen uppstod i svenskan i början av 1800-talet, och senast på 1830-talet. Längre gick det knappast att komma.

Det kan nämnas, att Ordbog over det danske sprog, ODS, ger ett belägg på motsvarande danska konstruktion från mitten av 1800-talet:

(4) I hendes Saloner samledes ikke, hvad man sædvanligt - naragtigt nok kalder Eliten af Selskabet.

Intressant nog nämns inte underligt/klokt nog-konstruktionen i Westerns norska riksmålsgrammatik från 1921 (Swan 1991). Swan drar den kanske lite djärva slutsatsen att detta sätt att bilda satsadverb ännu inte var produktivt i norskan i början av 1900-talet.

Den motsvarande engelska konstruktionen, ofta med optionellt enough som i exemplet strangely (enough), he didn't come, är belagd åtminstone sedan slutet av

[4] Ett fåtal svenska satsadverb utgörs enbart av adjektivets neutrumform (dvs. nog-konstruktionen behövs inte, och är vanligen inte möjlig): bestämt, eventuellt, faktiskt, följdenligt (eller följdenligt nog), omöjligt (dock bara i kontexter med kan), sannolikt, självfallet, självklart, skenbart, säkert och uppenbart. Ett betydligt vanligare satsadverbbildande suffix har traditionellt varit -en (troligen, antagligen etc.). Suffixet -vis (lyckligtvis etc.) och dess förhållande till nog behandlas i korthet i Malmgren 2014. 
1700-talet - i OED finns ett exempel från 1783. Man kan då åtminstone tänka tanken att den svenska och danska underligt/klokt nog-konstruktionen möjligen uppstått genom påverkan från engelskan, kanske via översättningslitteraturen. ${ }^{5}$

Drygt 10 år efter 2002, 2014, var Litteraturbanken redan i snabb tillväxt. Där påträffades inte så få belägg från 1830-talet av olika skönlitterära författare, däribland ett par som var något äldre än SAOB:s förstabelägg:

(5) [...] alla dessa tusende strunt-resonemanger åt alla håll som, ömkligt nog, bära namn af bildning [...].

(Almqvist, Dialog om sättet att sluta stycken, 1834)

(6) Besynnerligt nog blef föret med hvarje mil bättre.

(A. Tömeros, Brev och dagboksanteckningar III (brev 1833))

Det sista citatet var vid denna tidpunkt det äldsta belägg på underligt/klokt nogkonstruktionen som med säkerhet kunde påvisas. Både Almqvist och Törneros var representerade i Litteraturbanken med texter från före 1830, men i dessa texter hittades inga otvetydiga belägg på den nya typen av satsadverb. Två ställen i tidigare brev och dagböcker av Törneros förtjänar dock att citeras:

(7) [...] att han tappert nog slagit sig igenom prestexamen [...]

(8) [...] Det är märkvärdigt nog, att jag [...]

I det första citatet kan tappert nog tolkas både som satsadverb(ial) ("det var tappert av honom") och sättsadverb(ial) ("han slog sig tappert igenom"), men den senare tolkningen förefaller troligast. En poäng är emellertid att det är fullt möjligt att underligt/klokt nog-konstruktionen uppkommit via sådana dubbeltydiga fraser (som kunde kallas brofraser). I det andra citatet är märkvärdigt nog självfallet inte satsadverb(ial), men också denna konstruktionstyp kan ha främjat uppkomsten av underligt/klokt nog-konstruktionen (genom en sorts satsförkortning).

Tack vare Litteraturbanken gick det alltså att komma ett litet steg vidare 2014. För det första ökade sannolikheten för att underligt/klokt nog-konstruktionen uppstått i början av 1800-talet, kanske på 1810-talet eller 1820-talet. Och för det andra verkade det mycket troligt att den nya konstruktionen var i ganska allmänt bruk på den svenska parnassen redan på 1830-talet. (Se vidare Malmgren 2014.)

[5] Konstruktionen finns också i holländska, med ett förstabelägg från mitten av 1800-talet, däremot inte i tyska och knappast alls i de romanska och slaviska språken (med visst undantag för franska), enligt Ramat \& Ricca 1998. 


\section{[3] KONSTRUKTIONEN I NYARE SVENSKA KORPUSAR}

$\mathrm{Nu}$ är det 2020 och digitaliseringen av äldre texter har nått nya höjder. KB:s tidningskorpus framstår närmast som ett ymnighetshorn när det gäller tidiga underligt/klokt nog-belägg, som strax ska påvisas. Jag gick (2019) först igenom en lista med några tusen svenska adjektiv och antecknade dem som kunde tänkas ingå i underligt/klokt nog-uttryck. Sedan sökte jag på dessa uttryck (barnsligt nog, begripligt nog etc.) och markerade dem som hade förstabelägg tidigare än 1840 . Detta resulterade i listan i tabell 1 på nästa sida. ${ }^{6}$

Vad som genast faller i ögonen är här de två 1700-talsbeläggen. Det ska sägas, att båda uppträder i poesi, vilket möjligen kan göra dem mindre vittnesgilla. Men i och för sig förefaller åtminstone det första belägget otvetydigt:

(9) De Gåfwor, dem af Dig [Gud] vi lånt

Ha wi, beklagligt nog! ej nyttjat som wi böre

(Carlscronas wekoblad 1776)

(10) En Gång förmätet [ung. självöverskattande] nog, jag wille bjuda til At upför Wishets Berget klifwa

(Nytt och Gammalt 1784)

Här kan förmätet nog tolkas både som sättsadverbial och satsadverbial. På 1700talet kunde nog ha betydelsen 'mycket', och en parafras skulle kunna vara "En gång ville jag på ett mycket förmätet sätt bjuda till ..." (vid sidan av "jag ville bjuda till ..., vilket var förmätet"). Samma dubbeltydighet uppträder ofta hos de personvärderande adverben (jfr exempel (7) med tappert nog ovan), men inte ofta bland de situationsvärderande - beklagligt nog, underligt nog etc. kan knappast tänkas som sättsadverbial. Med viss tvekan förkastas därför det sista 1700-talsbelägget ovan, medan det första godtas - men också med tvekan. Man kan nämligen notera en liten detalj, utropstecknet efter nog. Det kan möjligen tolkas så att inskottet beklagligt nog inte är en helt integrerad del av satsen, utan ett s.k. annex för att använda en term som lanseras i Svenska Akademiens grammatik, SAG.

I övrigt lägger man märke till en visserligen ganska svag tendens i Tabell 1: de situationsvärderande adverben uppträder något tidigare än de personvärderande. Vi noterar å ena sidan beklagligt nog 1776 (visserligen alltså i poesi och kanske som annex), sällsamt nog 1805, besynnerligt nog 1808, underligt nog 1810 , olyckligt nog 1811, otroligt nog 1817, rysligt nog 1817 och märkligt nog 1824, och å andra sidan förnuftigt nog 1812, otacksamt nog 1812, naivt nog 1825, klokt nog 1826

[6] Återigen: KB:s material omfattar bara tidningstexter. Det är fullt möjligt att det går att hitta tidigare belägg $i$ andra typer av texter (dock knappast i Litteraturbanken). 
och barnsligt nog 1829. (Löjligt nog är ett gränsfall som kan föras till båda grupperna, men i första hand till den situationsvärderande gruppen.) Något tillspetsat skulle man kanske kunna säga, att de personvärderande adverben av underligt/klokt nog-typ bryter igenom på 1810-talet eller 1820-talet (och på bred front på 1830-talet), medan de situationsvärderande etablerar sig på allvar redan under 1800-talets första decennium.

\begin{tabular}{|c|c|}
\hline Satsdverb av underligt/klokt nog-typ & Årtal för första belägg \\
\hline barnsligt nog & 1829 \\
\hline begripligt nog & 1837 \\
\hline beklagligt nog & $1776(? !)$ \\
\hline besynnerligt nog & 1808 \\
\hline billigt nog (=rimligt nog) & 1831 \\
\hline blygsamt nog & 1835 \\
\hline elakt nog & 1831 \\
\hline fegt nog & 1830 \\
\hline frikostigt nog & 1837 \\
\hline fräckt nog & 1831 \\
\hline förargligt nog & 1835 \\
\hline förmätet nog & $1784(? !)$ \\
\hline förnuftigt nog & 1812 \\
\hline förskräckligt nog & 1832 \\
\hline förunderligt nog & 1827 \\
\hline klokt nog & 1826 \\
\hline löjligt nog & 1806 \\
\hline märkligt nog & 1824 \\
\hline märkvärdigt nog & 1827 \\
\hline naivt nog & 1825 \\
\hline naturligt nog & 1836 \\
\hline oblygt nog & 1829 \\
\hline oförlåtligt nog & 1834 \\
\hline olyckligt nog & 1811 \\
\hline otacksamt nog & 1812 \\
\hline otroligt nog & 1817 \\
\hline ovanligt nog & 1831 \\
\hline rysligt nog & 1817 \\
\hline sällsamt nog & 1805 \\
\hline underligt nog & 1810 \\
\hline ömkligt nog & 1834 \\
\hline
\end{tabular}

TABELL 1: Satsdverb av klokt nog-typ med förstabelägg före 1840 
[4] KONSTRUKTIONEN I NYARE NORSKA KORPUSAR

Om man söker i Nasjonalbibliotekets korpus över norska tidningar från decennierna före 1850 (www.bokhylla.no), får man också en ganska riklig skörd. Av naturliga skäl kan jag inte gå ner på samma detaljnivå som när det gällde svenska texter, men med det förbehållet är det äldsta påträffade belägget på underligt/klokt nok-konstruktionen i de norska texterna följande:

(11) Underligt nok contrastere de forhen omtalte Berømmelser over Prinds Christian Frederik med hvad der siges følgende St. 30

(Det Norske Nationalblad 15/2 1817)

Andra tidiga underligt/klokt nok-adverb i de norska tidningarna är selsomt nok (1820), forunderligt nok (1825) och utroligt nok (1836). Liksom i det svenska materialet verkar de situationsvärderande adverben uppträda något tidigare i de norska texterna än de personvärderande. Dock finns ett belägg på naivt nok från 1830, medan klokt nok faktiskt inte är belagt en enda gång under 1800-talet.

Också i det norska materialet finns flera exempel på att nok-frasen kanske snarare är annex än (integrerat) satsadverbial (jfr (9) ovan); observera ordföljden:

(12) [...] men, selsomt nok! den lange, ensomme Forvaring hade næsten bragt henne til at glemme hendes Sprog

(Morgenbladet 1825)

Det ser alltså ut som om den tidiga utvecklingen av underligt/klokt nok-konstruktionen i norska i stort sett är parallell med utvecklingen i svenska. I svenska verkar det finnas aningen tidigare förstabelägg, även om man inte räknar med poesibelägget från 1776. Om man bortser från det belägget, är det tidigaste engelska belägget fortfarande äldre än det äldsta svenska (och norska), och dessutom bör man kunna hitta betydligt äldre engelska belägg om man gör sökningar i större engelska 1700-talskorpusar. Det finns därför ingen anledning att revidera den förmodan som delvis gjordes i Malmgren 2014, att den svenska, danska och norska (och kanske holländska) underligt/klokt nog-konstruktionen uppstått under påverkan av motsvarande engelska konstruktion med enough.

Avslutningsvis ska vi gå drygt ett halvsekel framåt i tiden och se efter hur det såg ut i norska tidningar under 1900-talets första decennium, när den första riksmålsnormalen fastställdes och man kan tala om ett självständigt norskt skriftspråk (vid sidan av nynorska). Det ser faktiskt ut som om Swan (1991) har rätt i sin förmodan, att nok ännu inte är särskilt produktivt som satsadverbbildande 
suffix. Några få situationsvärderande satsadverb är väl företrädda, särskilt merkelig(t) nog, underlig(t) nok och karakteristisk nok (nästan 100 förekomster i tidningsmaterialet mellan 1900 och 1909), men de personvärderande tycks vara ganska sällsynta: exempelvis förekommer klokt nok inte en enda gång 1900-1909 och naivt nok 5 gånger. Det är därför kanske inte så konstigt att Western (1921) inte nämner underligt/klokt nog-konstruktionen.

Det är tydligt att de båda nationalbibliotekens jättekorpusar öppnar helt nya perspektiv för den språkhistoriska forskningen, i synnerhet (tack vare tidningsmaterialen) kanske forskningen kring de senaste 200-250 årens språkhistoria.

\section{LITTERATUR, TRYCKTA ARBETEN}

Malmgren, Sven-Göran. 2000. Projektet Det svenska ordförrådets utveckling 1800-2000. Utgångspunkter. Göteborg: Göteborgs universitet, Institutionen för svenska språket. (Rapporter från ORDAT. 1.)

Malmgren, Sven-Göran. 2002. Faktiskt, förstås och många andra. Om förändringar i det svenska formordssystemet under 1800- och 1900-talet. I Språk och stil 12 (ny följd), 97-146.

Malmgren, Sven-Göran. 2014. Konstigt nog, klokt nog ... Om en ganska ny typ av satsadverb i svenskan och andra språk. Fint språk / Good Language. Festskrift till Lars-Gunnar Andersson. Göteborg: Göteborgs universitet, Institutionen för svenska språket, 109-116. (Meijerbergs arkiv för svensk ordforskning. 41.)

ODS = Ordbog over det danske sprog. København 1918-56.

OED = Oxford English Dictionary. Oxford 1882-1928.

Ramat, Paolo \& Davide Ricca. 1998. Sentence Adverbs in the languages of Europe. I Johann van der Auwera (red.), Adverbial Constructions in the Languages of Europe. Berlin \& New York, 187-275.

$S A G=$ Andersson, Erik, Staffan Hellberg \& Ulf Teleman. 1999. Svenska Akademiens grammatik. Stockholm.

$S A O B=$ Ordbok över svenska språket utgiven av Svenska Akademien. Lund 1893. (I maskinläsbar och sökbar form: OSA.)

Swan, Toril. 1991. Adverbial Shifts: Evidence from Norwegian and English. I Dieter Kastovsky (red.), Historical English Syntax. Berlin \& New York, 409-438.

Western, August. 1921. Norsk riksmålsgrammatikk. Christiania. 
WNT = Woordenboek der Nederlandsche Taal. 's-Gravenhage/Leiden 1882-1998.

ELEKTRONISKA MATERIAL

Kungliga bibliotekets korpus över svenska dagstidningar. Stockholm, http://tidningar.kb.se

Litteraturbanken. Göteborgs universitet: Institutionen för svenska språket, http://litteraturbanken.se

Nasjonalbibliotekets korpus över norsk litteratur. Oslo, www.bokhylla.no

Språkbanken. Göteborgs universitet: Institutionen för svenska språket, http://spraakbanken.gu.se

KONTAKT

Sven-Göran Malmgren

Prof. emeritus, Göteborgs universitet

sg.malmgren@gmail.com 
